\title{
Propionibacterium acnes Types I and II Represent Phylogenetically Distinct Groups
}

\author{
Andrew McDowell, ${ }^{1}$ Susanna Valanne, ${ }^{1}$ Gordon Ramage, ${ }^{1}$ Michael M. Tunney, ${ }^{1}$ \\ Josephine V. Glenn, ${ }^{1}$ Gregory C. McLorinan, ${ }^{1}$ Ajay Bhatia, ${ }^{2}$ \\ Jean-Francois Maisonneuve, ${ }^{2}$ Michael Lodes, ${ }^{2}$ \\ David H. Persing, ${ }^{2}$ and Sheila Patrick ${ }^{1 *}$ \\ Department of Microbiology and Immunobiology, School of Medicine, Queen's University, Belfast, United Kingdom, ${ }^{1}$ \\ and Corixa Corporation, Infectious Disease Research Institute, Seattle, Washington ${ }^{2}$
}

Received 15 June 2004/Returned for modification 17 August 2004/Accepted 31 August 2004

\begin{abstract}
Although two phenotypes of the opportunistic pathogen Propionibacterium acnes (types I and II) have been described, epidemiological investigations of their roles in different infections have not been widely reported. Using immunofluorescence microscopy with monoclonal antibodies (MAbs) QUBPa1 and QUBPa2, specific for types I and II, respectively, we investigated the prevalences of the two types among $132 P$. acnes isolates. Analysis of isolates from failed prosthetic hip implants $(n=40)$ revealed approximately equal numbers of type I and II organisms. Isolates from failed prosthetic hip-associated bone $(n=6)$ and tissue $(n=38)$ samples, as well as isolates from acne $(n=22)$, dental infections $(n=8)$, and skin removed during surgical incision $(n$ = 18) were predominately of type I. A total of $11(8 \%)$ isolates showed atypical MAb labeling and could not be conclusively identified. Phylogenetic analysis of $P$. acnes by nucleotide sequencing revealed the $16 \mathrm{~S}$ rRNA gene to be highly conserved between types I and II. In contrast, sequence analysis of $r e c A$ and a putative hemolysin gene (tly) revealed significantly greater type-specific polymorphisms that corresponded to phylogenetically distinct cluster groups. All 11 isolates with atypical MAb labeling were identified as type I by sequencing. Within the $r e c A$ and $t l y$ phylogenetic trees, nine of these isolates formed a cluster distinct from other type I organisms, suggesting a further phylogenetic subdivision within type I. Our study therefore demonstrates that the phenotypic differences between $P$. acnes types I and II reflect deeper differences in their phylogeny. Furthermore, nucleotide sequencing provides an accurate method for identifying the type status of $P$. acnes isolates.
\end{abstract}

Propionibacterium acnes is an opportunistic pathogen implicated in late-stage prosthetic joint infections, acne vulgaris, endocarditis, endophthalmitis, osteomyelitis, and shunt-associated central nervous system infections $(2,5,7,33)$. Currently, routine diagnostic practices may underestimate the clinical importance of this anaerobic organism due to inefficient detection and isolation procedures, along with the traditionally held view that, due to its low virulence, its presence in clinical samples reflects contamination. While the opportunistic pathogenic potential of coagulase-negative staphylococci (CoNS), such as Staphylococcus epidermidis, is well recognized, the importance of $P$. acnes may still be overlooked (13), despite the fact that it produces more kinds of putative virulence determinants than CoNS $(5,38)$. This fact is illustrated by recent studies in which $P$. acnes was recovered as frequently as CoNS from the prosthetic hips of patients undergoing revision arthroplasty $(33,34)$.

As a member of the resident human microbiota, P. acnes is found predominantly in the sebaceous gland-rich areas of the skin in adults $(5,25)$. It has, however, also been isolated from the conjunctiva, the mouth, and the large intestine (7). It accounts for approximately half of the total skin microbiota (31),

\footnotetext{
* Corresponding author. Mailing address: Department of Microbiology and Immunobiology, School of Medicine, Queen's University, Grosvenor Road, Belfast, BT12 6BN, United Kingdom. Phone: 44 (0) 2890 632512. Fax: 44 (0) 2890 635024. E-mail: s.patrick@qub.ac.uk.
}

with an estimated density of $10^{2}$ to $10^{5}$ or $10^{6}$ organisms per $\mathrm{cm}^{2}(18,25)$. Studies by Johnson and Cummins (14) first revealed two distinct phenotypes of $P$. acnes, known as types I and II, that could be distinguished based on serological agglutination tests and cell wall sugar analysis. The GC contents and DNA homologies of types I and II were found to be similar to each other but significantly different from those of Propionibacterium granulosum and Propionibacterium avidum (14). Other methods for differentiating the two serotypes, based on bacteriophage (39) and fermentation typing $(10,16)$, as well as immunofluorescence with polyclonal antisera (11), have also been described. To date, serological methods have proved to be more specific and/or practical than other approaches for the differentiation of types I and II.

The roles that $P$. acnes types I and II play in various clinical infections, and the potential differences in their production of putative virulence factors, have not been widely examined. Furthermore, although serological and biochemical analyses of $P$. acnes have revealed two distinct phenotypic groups, no phylogenetic study of these biovars has been performed. Improvements in the methods used to differentiate P. acnes types I and II, and a better understanding of their phylogeny, will greatly aid epidemiological and virulence studies of this opportunistic pathogen and facilitate the investigation of potentially pathogenic strains associated with specific clinical conditions.

In this study, we have improved antibody-based identification of $P$. acnes types I and II by generating type-specific 
monoclonal antibodies (MAbs) that enable differentiation by immunofluorescence microscopy (IFM). We have also conducted a phylogenetic comparison of type I and II isolates recovered from various sources. We now report that the phenotypic differences observed by antibody labeling reflect deeper differences at the gene level, and we propose that types I and II represent phylogenetically distinct cluster groups.

\section{MATERIALS AND METHODS}

Bacterial strains. The following reference strains were from the National Collection of Type Cultures (NCTC; Colindale, England) or the American Type Culture Collection (ATCC; Manassas, Va.): P. acnes (NCTC 737; NCTC 10390), Propionibacterium granulosum (NCTC 10387), Staphylococcus aureus (NCTC 10788; ATCC 25923), Staphylococcus epidermidis (NCTC 11047), Staphylococcus haemolyticus (NCTC 11042), Staphylococcus hominis (NCTC 11320), Staphylococcus intermedius (NCTC 11048), Staphylococcus lugdunensis (NCTC 12217), Staphylococcus xylosus (NCTC 11043), Streptococcus equi (NCTC 3767), Streptococcus lactis (NCTC 66430), Streptococcus mitis (NCTC 3767), Streptococcus mutans (NCTC 10449), Streptococcus pyogenes (NCTC 11200), Streptococcus salivarius (NCTC 163034), Streptococcus sanguinis (NCTC 3753), Peptostreptococcus magnus (NCTC 11804), and Bacteroides fragilis (NCTC 9343). A total of $132 P$. acnes isolates were examined. Sixty-five isolates were recovered from failed prosthetic hip joints and associated bone and tissue samples, as detailed previously $(33,34)$. A total of 18 skin isolates were obtained from spinal operation incision sites after homogenization of skin samples as previously described $(33,34)$. In addition, a further 19 P. acnes isolates from tissue samples associated with failed prosthetic hips, as well as isolates recovered from patients with acne $(n=22)$ and dental $(n=8)$ infections, were kind gifts. Isolates of Corynebacterium diphtheriae, Corynebacterium hofmannii, Corynebacterium xerosis, and Propionibacterium avidum were provided by the culture collection of the Department of Microbiology and Immunobiology, Queen's University, Belfast, United Kingdom.

Bacterial culture. All anaerobic strains were grown on anaerobic blood agar (ABA) (CM0972; Oxoid Ltd., Basingstoke, England). Cultures were incubated at $37^{\circ} \mathrm{C}$ in an anaerobic cabinet (MACS MG 1000; Don Whitley Scientific, Shipley, England) under an atmosphere of $80 \% \mathrm{~N}_{2}, 10 \% \mathrm{CO}_{2}$, and $10 \% \mathrm{H}_{2}$. Aerobic coryneform strains were grown aerobically at $37^{\circ} \mathrm{C}$ on blood agar (BA). All Staphylococcus and Streptococcus strains were also grown at $37^{\circ} \mathrm{C}$ on BA. Isolates of $P$. acnes were identified by using the API 20A multitest identification system (BioMérieux, Basingstoke, England) in accordance with the manufacturer's instructions.

Fermentation tests. Fermentation reactions of $P$. acnes were studied on modified protease peptone yeast agar plates containing $40 \mathrm{mg}$ of bromocresol purple indicator (BDH, Poole, England)/liter and 1\% (wt/vol) sorbitol, erythritol, or ribose (Sigma-Aldrich Company Ltd., Poole, England). Organisms were grown anaerobically, as described above, and a positive fermentation reaction was noted if the agar plates turned yellow due to acid production. Fermentation biotypes (biotypes 1 to 5) based on all three substrates were determined for culture collection reference strains NCTC 737 and NCTC 10390; strains AT1, DW1, and ED2, used for MAb production; and strains with atypical MAb labeling $(10,16)$. For all other isolates, only sorbitol fermentation was routinely investigated for type I organisms.

Production of MAbs. MAbs were generated by using the protocol described previously (33). Four BALB/c mice were immunized with killed whole cells $\left(10^{8}\right.$ $\mathrm{CFU} / \mathrm{ml}$ ) of the $P$. acnes strain AT1 (type I; biotype 3 ), while a further four BALB/c mice were immunized with a combination of killed whole cells of $P$. acnes strains DW1 and ED2 (type II; biotype 2). Hybridoma cell lines producing $P$. acnes-specific MAbs were cloned by limiting dilution (9).

IFM. A modification of the IFM procedure described by Patrick et al. (27) was performed on pure cultures. Briefly, bacterial cultures were grown for $18 \mathrm{~h}$ on $\mathrm{ABA}$ or $\mathrm{BA}$, and a suspension of $10^{8} \mathrm{CFU} / \mathrm{ml}$ in $0.01 \mathrm{M}$ phosphate-buffered saline (PBS, consisting of $0.15 \mathrm{M} \mathrm{NaCl}, 0.0075 \mathrm{M} \mathrm{Na}_{2} \mathrm{HPO}_{4}$, and $0.0025 \mathrm{M}$ $\mathrm{NaH}_{2} \mathrm{PO}_{4} \cdot 2 \mathrm{H}_{2} \mathrm{O}[\mathrm{pH}$ 7.4]) was prepared. Samples $(10 \mu \mathrm{l})$ were then applied to multiwell slides, air dried, and fixed in $100 \%$ methanol for $10 \mathrm{~min}$ at $-20^{\circ} \mathrm{C}$. Undiluted human AB serum (30 $\mu \mathrm{l}$ ) (Sigma-Aldrich Ltd.) was added as a blocking agent, and the slides were incubated at $37^{\circ} \mathrm{C}$ for $45 \mathrm{~min}$. The slides were then washed in $0.01 \mathrm{M}$ PBS containing $0.5 \%$ ( $\mathrm{vol} / \mathrm{vol}$ ) AB serum for $20 \mathrm{~min}$. The appropriate undiluted MAb-containing supernatant $(30 \mu \mathrm{l})$ was added to each well of the slides and incubated for $45 \mathrm{~min}$ at $37^{\circ} \mathrm{C}$. After a wash, as before, wells were incubated with a 1:100 dilution of a fluorescein isothiocyanate (FITC)- conjugated goat anti-mouse antibody (Sigma-Aldrich Ltd.) in a $0.1 \%$ Evans blue (Merck Sharp \& Dome, Hoddesdon, England) counterstain $(30 \mu \mathrm{l})$ for $45 \mathrm{~min}$ at $37^{\circ} \mathrm{C}$. Slides were then washed and mounted in glycerol-PBS containing an antiphotobleaching agent (Citifluor; Agar Scientific Ltd., Stansted, England), and examined by using a Leitz Dialux 20 fluorescence microscope. A selection of slides was also examined by confocal laser scanning microscopy.

Immunogold labeling for electron microscopy. P. acnes cultures were suspended in distilled water, and several drops were applied to a glow-discharged Formvar carbon-coated copper grid (400 mesh). Grids were air dried and immunogold labeled as described previously (23). The samples were then incubated with PBS containing 1\% (wt/vol) bovine serum albumin (Sigma-Aldrich Ltd.) for $10 \mathrm{~min}$, followed by an undiluted MAb-containing supernatant for $90 \mathrm{~min}$ at room temperature. The grids were washed in $20 \mathrm{mM}$ Tris- $\mathrm{HCl}$ (pH 8.2) containing $0.9 \mathrm{M} \mathrm{NaCl}$ and $0.1 \%$ (wt/vol) bovine serum albumin before incubation with goat anti-mouse immunoglobulin $\mathrm{G}(\mathrm{IgG})$ conjugated with 15-nm-diameter gold particles (Amersham Biosciences, Little Chalfont, England) for $90 \mathrm{~min}$. After a wash in distilled water, bacteria were negatively stained with ammonium molybdate $(2 \%[\mathrm{wt} / \mathrm{vol}])$ and examined with a transmission electron microscope (Philips CM10).

Preparation of bacterial whole-cell lysates and cell wall extracts. Whole cells (25 mg [wet weight] $/ \mathrm{ml}$ ) were suspended in distilled water and disrupted by ultrasound (Soniprep 150; amplitude, $26 \mu \mathrm{m}$ ) for $5 \mathrm{~min}$ at $4^{\circ} \mathrm{C}$. Intact lyophilized bacterial cell walls were obtained by using the method of Hancock and Poxton (8). Sterile distilled water was added to the lyophilized cell walls $(10 \mathrm{mg} / \mathrm{ml})$ prior to ultrasonication as described above.

Sodium dodecyl sulfate-polyacrylamide gel electrophoresis (SDS-PAGE) and immunoblotting. Sonicates of whole cells and purified cell wall extracts were analyzed on $9.0 \%$ (wt/vol) discontinuous polyacrylamide gels according to the method of Laemmli (17). Separated components were then transferred to a nitrocellulose membrane (Protran; pore size, $0.45 \mu \mathrm{m}$; Schleicher and Schuell, Dassel, Germany) by using a Mini TransBlot apparatus (Bio-Rad Laboratories Ltd., Hemel Hampsted, England) according to the manufacturer's instructions. Immunoblotting was carried out as previously described with minor modifications (26). In brief, the nitrocellulose membrane was blocked with $0.01 \mathrm{M}$ PBS containing $0.05 \%$ (vol/vol) Tween 20 (PBS-Tween) and $0.5 \%$ (wt/vol) nonfat milk powder (Marvel; Premier Brands, Spalding, England). After a wash with PBS-Tween, the nitrocellulose membrane was incubated in an undiluted MAbcontaining supernatant. The nitrocellulose membrane was then washed in PBSTween before incubation with alkaline phosphatase-conjugated goat anti-mouse IgG $(\mathrm{H}+\mathrm{L})$ (Sigma-Aldrich Ltd.). Bound MAbs were detected by using an alkaline phosphatase conjugate substrate kit containing nitroblue tetrazolium and 5-bromo-4-chloro-3-indolylphosphate (Bio-Rad Laboratories Ltd.). Where required, and before the addition of the MAb-containing supernatant, nitrocellulose strips containing electroblotted proteins were preincubated for $1 \mathrm{~h}$ at $37^{\circ} \mathrm{C}$ with different concentrations of proteinase K (Sigma-Aldrich Ltd.) in $20 \mathrm{mM}$ Tris-HCl buffer ( $\mathrm{pH} 8.0$ ) containing $2 \mathrm{mM} \mathrm{CaCl}_{2}$ or with different concentrations of sodium-meta-periodate (Sigma-Aldrich Ltd.) in citrate buffer ( $\mathrm{pH} 7.5$ ).

PCR analysis. Bacterial genomic DNA was prepared by boiling a suspension $(0.5 \mathrm{ml})$ of freshly cultured cells in sterile PCR-grade water (LAL grade; Cambrex Bioscience, Wokingham, England) for $10 \mathrm{~min}$. The suspension was then cooled before centrifugation at $15,000 \times g$ for $2 \mathrm{~min}$. The resulting supernatant containing genomic DNA was stored at $-20^{\circ} \mathrm{C}$ prior to analysis. PCR amplifications were carried out using a Gene Cycler (PT-225; MJ Research, Inc., Waltham, Mass.). Samples contained $1 \times$ PCR buffer, $200 \mu \mathrm{M}$ each deoxynucleoside triphosphate (Amersham Biosciences), $200 \mu \mathrm{M}$ each primer (Invitrogen Life Technologies, Paisley, Scotland), $1.5 \mathrm{mM} \mathrm{MgCl}_{2}, 1.25 \mathrm{U}$ of Platinum Taq DNA polymerase (Invitrogen Life Technologies), and $2.5 \mu$ l of bacterial lysate in a total volume of $25 \mu \mathrm{l}$. The $16 \mathrm{~S}$ rRNA gene of $P$. acnes $(1,484 \mathrm{bp}$; positions 3 to 1486 of GenBank sequence AB042288) was amplified by using the published universal primers UFPL (5'-AGTTTGATCCTGGCTCAG- $\left.3^{\prime}\right)$ and URPL (5'GGTTACCTTGTTACGACTT- $\left.3^{\prime}\right)(20)$. The $P$. acnes rec $A$ and $t$ ly genes were amplified by using primers directed to downstream and upstream flanking sequences of each open reading frame, thus facilitating accurate sequence determination of the $5^{\prime}$ and $3^{\prime}$ ends of each open reading frame. The $\operatorname{rec} A$ primers PAR-1 ( -96 to -75$)$ (5'-AGCTCGGTGGGGTTCTCTCATC-3') and PAR-2 $(+1105$ to +1083$)\left(5^{\prime}\right.$-GCTTCCTCATACCACTGGTCATC- $\left.3^{\prime}\right)$ generated a 1,201-bp amplicon, while the tly primers PAT-1 ( -85 to -65$)\left(5^{\prime}\right.$-CAGGACG TGATGGCAATGCGA-3') and PAT-2 (+824 to +803) (5'-TCGTTCACAAG ACCACAGTAGC-3') generated a 909-bp amplicon. Samples were initially heated at $95^{\circ} \mathrm{C}$ for $3 \mathrm{~min}$, followed by 35 cycles consisting of $1 \mathrm{~min}$ at $95^{\circ} \mathrm{C}, 30 \mathrm{~s}$ at $55^{\circ} \mathrm{C}$, and $1.5 \mathrm{~min}$ at $72^{\circ} \mathrm{C}$. The PCR was completed with a final extension step at $72^{\circ} \mathrm{C}$ for $10 \mathrm{~min}$. A negative control (water) was included in all experiments. All PCR products were analyzed by electrophoresis on $1 \%(\mathrm{wt} / \mathrm{vol})$ agarose gels 
(Invitrogen Life Technologies) containing $1 \times$ Tris-acetate-EDTA buffer. Molecular size markers (1-Kb Plus DNA ladder; Invitrogen Life Technologies) were run in parallel on all gels. Resolved DNA products were stained with ethidium bromide and viewed under UV light.

Nucleotide sequence analysis. PCR products were purified by using a QIAquick PCR purification kit (QIAGEN, Crawley, England). Sequencing reactions were performed using ABI PRISM Ready Reaction Terminator cycle sequencing kits (Perkin-Elmer Applied Biosystems, Foster City, Calif.) according to the manufacturer's instructions. Samples were analyzed on an ABI PRISM 3100 DNA sequencer (Perkin-Elmer Applied Biosystems). Raw sequences from both DNA strands were obtained by using the appropriate forward and reverse primers. Internal sequencing primers were also used to facilitate determination of the larger 16S rRNA gene sequence.

Phylogenetic analysis. The phylogenetic relationships of $r e c A$ and $t l y$ genes were determined by using the Data Analysis in Molecular Biology and Evolution (DAMBE) software (http://web.hku.hk/ xxia/software/software.htm). Multiple sequence alignments were performed by using the CLUSTAL W algorithm (32) and were exported into the DAMBE program. Phylogenetic trees were constructed by the maximum-parsimony method and the neighbor-joining method using the Jukes-Cantor-based algorithm. The sequence input order was randomized, and bootstrapping resampling statistics were performed using 100 data sets for each analysis. Analysis was performed on a selection of isolates chosen to represent different nucleotide sequences.

Nucleotide sequence accession numbers. Table 1 summarizes the $P$. acnes type I and II isolates which were examined for $16 \mathrm{~S}$ rRNA, recA, and tly gene sequences. Nucleotide sequences were submitted to GenBank, and each was assigned an accession number as shown in Table 1.

\section{RESULTS}

MAb reactivity. Two MAbs (QUBPa1 and QUBPa2) were selected on the basis of their reactivities with $P$. acnes reference strains whose type status was inferred from sugar fermentation reactions. Immunoreactivity was consistent upon repeated testing and was independent of whether the bacterial cells were prepared from plate or broth culture.

QUBPa1 reacted with the cell surface antigens of the $P$. acnes type I reference strain NCTC 737 (biotype 3) (Fig. 1A). IFM and immunoelectron microscopy revealed that the surface antigen localized at the apices and septa of a variable proportion of $P$. acnes cells (Fig. 1A and 2). Within a population, at least $95 \%$ of the bacterial cells were labeled with the MAb. QUBPa2 reacted with a cell surface antigen of the $P$. acnes type II reference strain NCTC 10390 (biotype 2) (Fig. 1B). Complete labeling of the bacterial surface by QUBPa2 was observed upon IFM (Fig. 1B). All cells within the population were labeled. QUBPa1 and QUBPa2 showed no reaction with NCTC 10390 and NCTC 737, respectively, as detected by conventional fluorescence microscopy or confocal laser scanning microscopy, even with a 10 -fold increase in green channel laser power (data not shown).

Both MAbs were nonreactive with other cutaneous Propionibacterium spp., with the coryneform bacteria $C$. diphtheriae, C. hofmannii, and C. xerosis, and with B. fragilis, Peptostreptococcus magnus, and all Staphylococcus and Streptococcus strains, as detailed in Materials and Methods.

Antigen characterization. The antigens interacting with QUBPa1 and QUBPa2 were characterized by SDS-PAGE and immunoblotting on sonicate samples from whole cells and purified cell wall extracts. With QUBPa1, two bands of 61 and 68 $\mathrm{kDa}$ were observed for whole-cell sonicates of the $P$. acnes reference strain NCTC 737 (type I) (Fig. 3A). Identical results were also obtained with $P$. acnes type I isolates (data not shown). When cell wall sonicates of NCTC 737 were analyzed, only one band of $68 \mathrm{kDa}$ was detected (Fig. 3A). With
QUBPa2, a diffuse band(s) or smear ranging from 30 to $40 \mathrm{kDa}$ and a discrete band at $21 \mathrm{kDa}$ were observed for whole-cell sonicates of the $P$. acnes reference strain NCTC 10390 (type II) (Fig. 3B). Similar results were obtained with $P$. acnes type II isolates (data not shown). Analysis of cell wall sonicates of NCTC 10390 revealed a similar banding pattern (Fig. 3B). No reactivity of QUBPa1 or QUBPa2 with whole-cell preparations of $P$. acnes NCTC 10390 or NCTC 737, respectively, was observed (Fig. 3).

To characterize the antigens further, immunoblots of wholecell sonicates from NCTC 737 and NCTC 10390 were treated with proteinase $\mathrm{K}$ or sodium-meta-periodate prior to incubation with the MAbs. With immunoblots of NCTC 737, the type I antigen reactivity with QUBPa1 was sensitive to a proteinase $\mathrm{K}$ concentration of $7.8 \times 10^{-4} \mathrm{mg} / \mathrm{ml}$ (Fig. 4A). Proteinase K treatment of whole cells prior to IFM analysis also revealed a similar diminution in QUBPa1 reactivity. Treatment of blots with sodium-meta-periodate had no effect on reactivity (data not shown). With NCTC 10390, type II antigen reactivity with QUBPa2 was sensitive to a sodium-meta-periodate concentration of $5 \times 10^{-2} \mathrm{M}$ (Fig. 4B). Treatment of whole cells with sodium-meta-periodate prior to IFM analysis produced a similar reduction in QUBPa2 reactivity. Treatment of blots with proteinase $\mathrm{K}$ had no effect on QUBPa2 reactivity (data not shown).

IFM analysis of $\boldsymbol{P}$. acnes isolates. IFM analysis of 132 isolates of $P$. acnes with QUBPa1 and QUBPa2 identified 87 $(66 \%)$ as type I and $34(26 \%)$ as type II (Table 2). Approximately equal numbers of type I and type II isolates were recovered directly from failed hip prostheses (Table 2). Isolates from associated bone and tissue samples were predominately of type I, as were the majority of isolates recovered from patients with acne or dental (periodontitis, pericoronitis, and endodontic) infections and isolates recovered from skin removed at the time of surgical incision (Table 2). A total of 11 isolates $(8 \%)$ gave atypical labeling with our MAbs (Table 1). Nine isolates (CK17, JMK9, LED2, MMG9, RM9, TON9, W1392, W1998, WMK9) displayed no reaction with MAb QUBPa1 but were identified as type I by virtue of their capacity to ferment sorbitol, a characteristic of some type I, but no type II, organisms. These isolates did, however, react with QUBPa2, but with significantly reduced fluorescence intensity and with an uncharacteristic reduction in the proportion of the bacterial population labeled with the MAb. This group of $P$. acnes organisms was recovered from failed prosthetic hip implants and associated tissue, patients with acne and dental infections, and skin wounds. Additional analysis with erythritol and ribose sugars revealed that all organisms within this atypical grouping shared the same fermentation biotype (biotype 1). A further two isolates (PV66 and PV93) reacted with both QUBPa1 and QUBPa2. Isolate PV66 exhibited a weak reaction with QUBPa1 but a strong reaction with QUBPa2. In contrast, PV93 was strongly positive with QUBPa1 but also displayed weak reactivity with QUBPa2. Neither of these isolates fermented sorbitol.

The remaining $92 \%$ of $P$. acnes isolates $(n=121)$ reacted with either QUBPa1 or QUBPa2, and no cross-reaction between the two MAbs was observed. The visual pattern of the MAb labeling (apex and septum or complete cell surface labeling [Fig. 1]), as well as the proportion of cells labeled, was 
TABLE 1. Comparison of $P$. acnes isolates by sorbitol fermentation, MAb labeling, and nucleotide sequence analyses

\begin{tabular}{|c|c|c|c|c|c|c|c|}
\hline P. acnes isolate and source & $\begin{array}{c}\text { Sorbitol } \\
\text { fermentation }\end{array}$ & $\begin{array}{c}\text { Type by MAb } \\
\text { labeling }^{a}\end{array}$ & $\begin{array}{l}\text { 16S rRNA } \\
\text { accession no. }\end{array}$ & $\begin{array}{c}r e c A \\
\text { accession no. }\end{array}$ & $\begin{array}{l}\text { Type by } r e c A \\
\text { sequencing }\end{array}$ & $\begin{array}{c}\text { tly accession } \\
\text { no. }\end{array}$ & $\begin{array}{l}\text { Type by } t l y \\
\text { sequencing }^{e}\end{array}$ \\
\hline \multicolumn{8}{|l|}{ Reference collection } \\
\hline NCTC 737 & + & I & AB042288 & AY642055 & I & AY527219 & I \\
\hline NCTC 10390 & - & II & AY642044 & AY642061 & II & AY644409 & II \\
\hline \multicolumn{8}{|l|}{ Acne } \\
\hline P6 & + & I & & AY642071 & I & & ND \\
\hline P9 & + & I & & AY642072 & I & & ND \\
\hline P24 & - & II & AY642046 & AY642058 & II & AY644406 & II \\
\hline PV37 & + & I & & AY642068 & I & AY644414 & $\mathrm{I}$ \\
\hline PV58 & + & I & & AY642073 & I & & ND \\
\hline PV66 & - & Atypical & AY642041 & AY642062 & I & AY644410 & I \\
\hline PV93 & - & Atypical & AY642043 & AY642063 & I & AY644411 & I \\
\hline $\mathrm{P} 135$ & + & I & & AY642074 & I & & ND \\
\hline P136 & + & I & & AY642075 & I & & ND \\
\hline \multicolumn{8}{|l|}{ Skin incision } \\
\hline JMK9 & + & Atypical & & AY642095 & I & AY644421 & I \\
\hline MMG9 & + & Atypical & & AY642094 & I & AY644420 & I \\
\hline TON9 & + & Atypical & & AY642096 & I & AY644422 & I \\
\hline WMK9 & + & Atypical & & AY642093 & I & AY644419 & I \\
\hline RM9 & + & Atypical & AY642050 & AY642070 & I & AY644416 & I \\
\hline \multicolumn{8}{|l|}{ Dental $^{b}$} \\
\hline W513 & + & I & & AY642079 & I & & ND \\
\hline W633 & + & I & & AY642080 & I & & ND \\
\hline W891 & + & I & & AY642081 & I & & ND \\
\hline W1034 & + & I & & AY642076 & I & & ND \\
\hline W1392 & + & Atypical & AY642051 & AY642059 & I & AY644407 & I \\
\hline W1973 & + & I & & AY642077 & I & & ND \\
\hline W1998 & + & Atypical & & AY642078 & I & AYY644417 & I \\
\hline \multicolumn{8}{|l|}{ Prosthesis ${ }^{c}$} \\
\hline $\mathrm{AT}^{d}$ & + & I & AY642048 & AY642082 & I & & ND \\
\hline ATB1 & - & II & & AY642087 & II & & ND \\
\hline CK17 & + & Atypical & & AY642092 & I & AY644418 & I \\
\hline $\mathrm{DW} 1^{d}$ & - & II & & AY642083 & II & & ND \\
\hline ED1 & - & II & & AY642069 & II & AY644415 & II \\
\hline $\mathrm{ED}^{d}{ }^{d}$ & - & II & AY642052 & AY642084 & II & & ND \\
\hline ET1 & - & II & & AY642085 & II & & ND \\
\hline JP1B & - & II & AY642053 & AY642065 & II & AY644413 & II \\
\hline JR2 & + & I & & AY642086 & I & & ND \\
\hline $\mathrm{KC} 1$ & - & II & & AY642066 & II & & ND \\
\hline L1958 & + & $\mathrm{I}$ & AY642042 & AY642056 & I & AY644404 & I \\
\hline LED2 & + & Atypical & AY642049 & AY642060 & I & AY644408 & I \\
\hline RB1B & - & II & & AY642067 & II & & ND \\
\hline RM1 & + & I & & AY642097 & I & AY644423 & I \\
\hline RM4 & - & II & AY642047 & AY642057 & II & AY644405 & II \\
\hline SG2 & - & II & AY642045 & AY642064 & II & AY644412 & II \\
\hline SR2 & - & II & & AY642088 & II & & ND \\
\hline TFJ2 & - & II & & AY642089 & II & & ND \\
\hline WD1 & - & II & AY642054 & AY642090 & II & & ND \\
\hline WD2 & - & II & & AY642091 & II & & ND \\
\hline
\end{tabular}

${ }^{a}$ Some isolates gave atypical labeling with MAbs QUBPa1 and QUBPa2.

${ }^{b}$ Isolates recovered from patients with periodontitis, pericoronitis, and endodontic infections.

${ }^{c}$ Isolates recovered directly from prosthetic hips or associated bone and tissue samples.

${ }^{d}$ Isolates used for the generation of MAbs QUBPa1 and QUBPa2.

${ }^{e} \mathrm{ND}$, not determined.

also characteristic of the $P$. acnes type I or II reference strain (NCTC 737 or NCTC 10390). All isolates conclusively identified as type II by use of our MAbs did not ferment sorbitol.

Nucleotide sequence analysis. All nucleotide sequencing was carried out on pooled PCR products to eliminate potential inaccuracies that can arise in the sequencing of individually cloned PCR products. A total of 15 P. acnes isolates, assigned to type I or type II on the basis of both MAb labeling and fermentation profiles, were selected for systematic analysis of 16S rRNA (Table 1). By using the universal bacterial $16 \mathrm{~S}$ rRNA-based primers UFPL and URPL, a 1,484-bp product was amplified from all strains. Nucleotide sequence analysis with UFPL and URPL, as well as internal 16S rRNA-based primers, produced a complete sequence. Sequence analysis of 
(A)

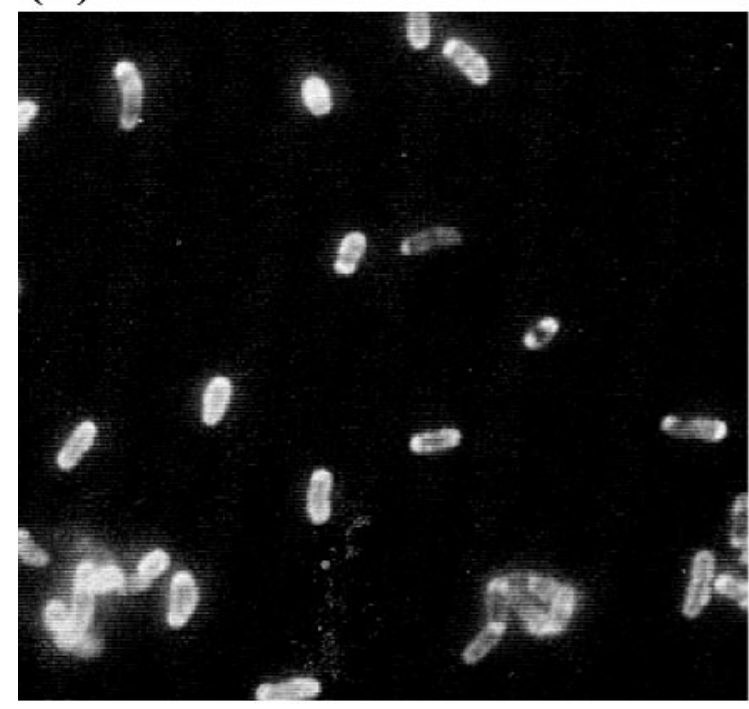

(B)

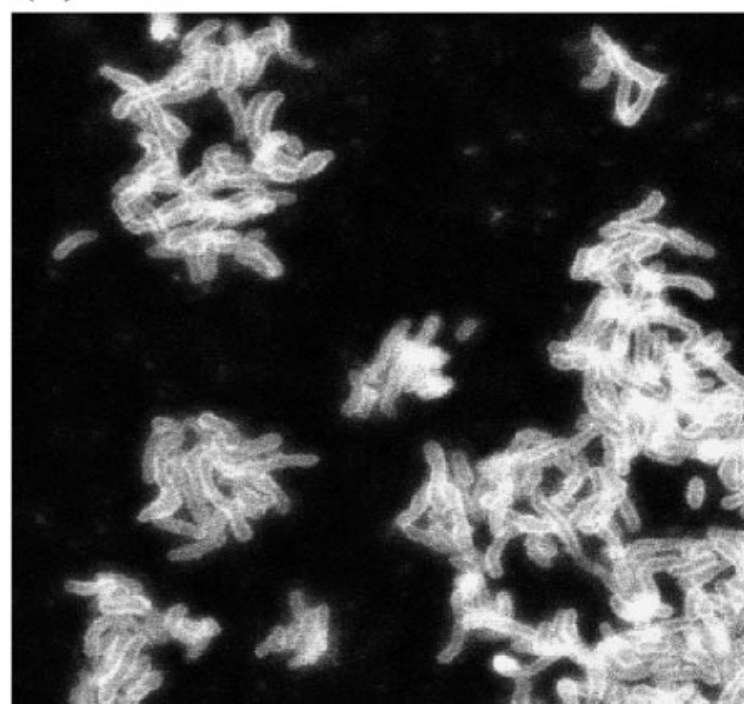

FIG. 1. Micrographs of $P$. acnes immunolabeled with a mouse MAb and an FITC-conjugated anti-mouse antibody. Bacteria were counterstained with Evans blue and viewed with a combined red/green filter ( $\times 100$ objective). (A) Reference strain NCTC 737 (type I) reacted with MAb QUBPa1; (B) reference strain NCTC 10390 (type II) reacted with MAb QUBPa2.

the 16S rRNA gene from $P$. acnes NCTC 737 was carried out as an internal control. The resulting sequence was identical to the previously published 16S rRNA gene for this strain (GenBank accession no. AB042288). Multiple sequence alignments of the 1,484-bp 16S rRNA genes from $P$. acnes types I and II $(n=15)$ revealed $>99.5 \%$ sequence identity. Only one typespecific polymorphism, at position 827 (numbering corresponds to GenBank accession no. AB042288), was observed. This corresponded to the nucleotide $\mathrm{T}$ in type I strains and $\mathrm{C}$ in type II strains.

Phylogenetic analyses of $P$. acnes types I and II based on the rec $A$ gene and a putative hemolysin gene (tly), both of which we identified from the draft genome sequence of NCTC 737 (property of Corixa Corporation, Seattle, Wash.), were also carried out. By use of PAR-1 and PAR-2, 1,201-bp products were amplified from the recA genes of NCTC 737 and NCTC 10390 as representatives of the two $P$. acnes types. Sequence

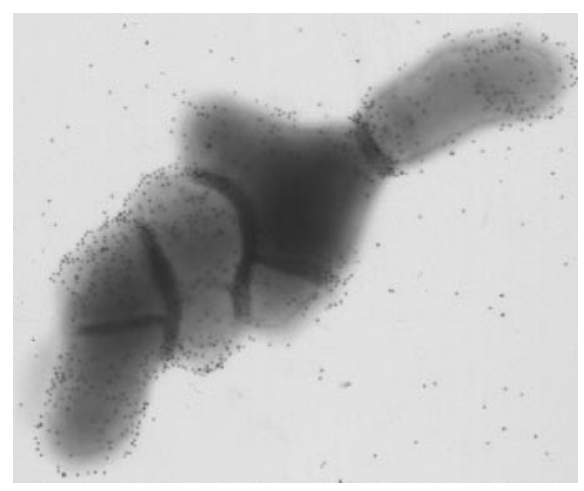

FIG. 2. Electron micrograph of $P$. acnes NCTC 737 (type I), immunolabeled with MAb QUBPa1 and an anti-mouse IgG conjugated with 15-nm-diameter gold particles, and negatively stained with ammonium molybdate. Note labeling at the septa and apices of cells. analysis of $P$. acnes NCTC 737 served as an internal control. The resulting rec $A$ sequence for our NCTC 737 internal-control strain was identical to the NCTC 737 genome sequence for recA (GenBank accession no. AY642055). Alignment of the 1,047-bp rec $A$ genes from NCTC 737 and NCTC 10390 revealed 10 type-specific differences ( $99 \%$ sequence identity). To facilitate phylogenetic analysis, we sequenced the $\operatorname{rec} A$ gene from a further $41 P$. acnes strains isolated from different clinical sources and selected to represent types I and II (Table 1).

By use of PAT-1 and PAT-2, 909-bp products were amplified from the putative hemolysin genes of NCTC 737 and NCTC 10390. The resulting tly sequence for our NCTC 737 internalcontrol strain was identical to the NCTC 737 genome sequence for tly (GenBank accession no. AY527219). Alignment of the 777-bp tly genes from NCTC 737 and NCTC 10390 revealed 18

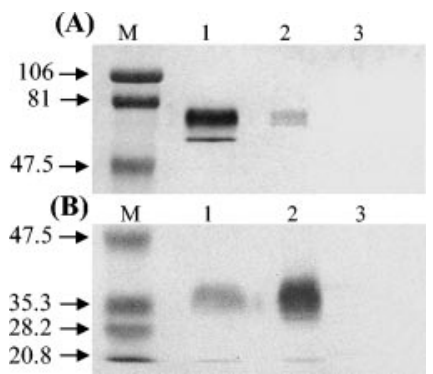

FIG. 3. Immunoblots of $P$. acnes with MAbs QUBPa1 and QUBPa2. (A) Labeling with QUBPa1. Lanes: M, molecular weight markers (in thousands); 1 , whole-cell sonicate preparation of NCTC 737; 2, purified cell wall sonicate preparation of NCTC 737; 3 , wholecell sonicate preparation of NCTC 10390. (B) Labeling with QUBPa2. Lanes: M, molecular weight markers (in thousands); 1, whole-cell sonicate preparation of NCTC 10390; 2, purified cell wall sonicate preparation of NCTC 10390; 3, whole-cell sonicate preparation of NCTC 737. 

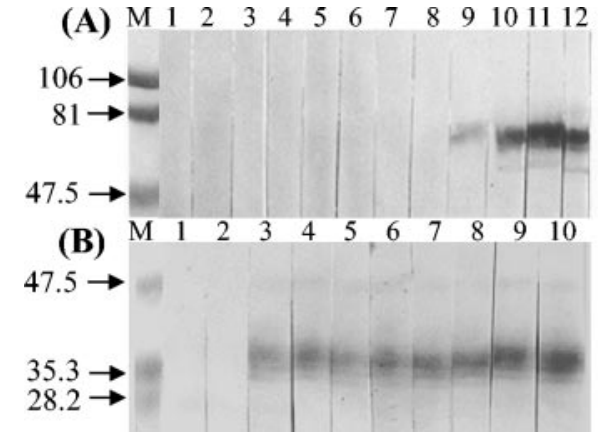

FIG. 4. Effects of proteinase $\mathrm{K}$ and sodium-meta-periodate treatments on $P$. acnes reactivities with MAbs QUBPa1 and QUBPa2. (A) QUBPa1 reactivity with proteinase K-treated whole-cell sonicate preparations. Lane $\mathrm{M}$, molecular weight markers (in thousands). Lanes 1 to 12 contain the following concentrations (in milligrams per milliliter) of proteinase $\mathrm{K}: 10^{-1}$ (lane 1), $5 \times 10^{-2}$ (lane 2), $2.5 \times 10^{-2}$ (lane 3), $1.25 \times 10^{-2}$ (lane 4), $6.25 \times 10^{-3}$ (lane 5), $3.12 \times 10^{-3}$ (lane 6), $1.56 \times 10^{-3}$ (lane 7), $7.81 \times 10^{-4}$ (lane 8), $3.90 \times 10^{-4}$ (lane 9), $1.95 \times 10^{-4}$ (lane 10), $9.76 \times 10^{-5}$ (lane 11), and $4.88 \times 10^{-5}$ (lane 12). (B) QUBPa2 reactivity with sodium-meta-periodate-treated whole-cell sonicate preparations. Lane $\mathrm{M}$, molecular weight markers (in thousands). Lanes 1 to 10 contain the following molar concentrations of sodium-meta-periodate: $10^{-1}$ (lane 1), $5 \times 10^{-2}$ (lane 2), 2.5 $\times 10^{-2}$ (lane 3), $1.25 \times 10^{-2}$ (lane 4), $6.25 \times 10^{-3}$ (lane 5), $3.12 \times$ $10^{-3}$ (lane 6), $1.56 \times 10^{-3}$ (lane 7), $7.81 \times 10^{-4}$ (lane 8), $3.90 \times 10^{-4}$ (lane 9), and $1.95 \times 10^{-4}$ (lane 10$)$.

type-specific differences (98\% sequence identity). For phylogenetic analysis, we sequenced the tly gene from a further $19 P$. acnes strains isolated from different sources and selected to represent types I and II (Table 1).

Phylogenetic analysis of $\operatorname{rec} A$ and $t l y$. Phylogenetic trees of $P$. acnes based on $\operatorname{rec} A$ and tly gene sequences were constructed. The rec $A$ and tly gene sequences from Helicobacter pylori (GenBank accession no. U13756 and AE000615) and Streptococcus agalactiae (GenBank accession no. AF326345 and NC_004116) were used as outgroups for our phylogenetic analysis, which was performed using the maximum-parsimony and neighborjoining methods. After 100 bootstrapping replications, the $\operatorname{rec} A$ and tly consensus trees derived by using the two methods gave

TABLE 2. Reactivities of $P$. acnes isolates with MAbs QUBPa1 and QUBPa2

\begin{tabular}{|c|c|c|c|c|}
\hline \multirow{2}{*}{ Source } & \multicolumn{3}{|c|}{$\begin{array}{l}\text { No. of isolates with the following } \\
\text { reactivity ( } \% \text { sorbitol fermenters): }\end{array}$} & \multirow{2}{*}{ Total } \\
\hline & QUBPa1 & QUBPa2 & Atypical & \\
\hline \multicolumn{5}{|c|}{ Prosthetic hips } \\
\hline Implant & $19(79)$ & $20(0)$ & $1(100)$ & 40 \\
\hline Bone $^{a}$ & $5(80)$ & $1(0)$ & 0 & 6 \\
\hline Tissue $^{a}$ & $29(83)$ & $8(0)$ & $1(100)$ & 38 \\
\hline \multicolumn{5}{|l|}{ Skin } \\
\hline Acne & $19(100)$ & $1(0)$ & $2(0)$ & 22 \\
\hline Incision & $9(100)$ & $4(0)$ & $5(100)$ & 18 \\
\hline Dental & $6(100)$ & 0 & $2(100)$ & 8 \\
\hline Total & $87(88.5)$ & $34(0)$ & $11(82)$ & 132 \\
\hline
\end{tabular}

\footnotetext{
${ }^{a}$ Bone and tissue associated with failed prosthetic hip implant.
}

the same topology, with type I and II strains forming distinct cluster groups. Only the consensus trees obtained by using the neighbor-joining method are shown (Fig. 5). Both the $\operatorname{rec} A$ and tly phylogenies of $P$. acnes were highly distinct from unrelated species selected as outgroups for the trees (bootstrap values, $100 \%$ ). Phylogenetic trees of $\mathrm{rec} A$ and tly based on protein translation of each nucleotide sequence revealed the same clustering of types I and II as distinct phylogenetic groups, even though the protein sequences were less discriminatory than the nucleotide sequences (data not shown). Phylogenetic analysis of the $\operatorname{rec} A$ and tly sequences from all 11 isolates with atypical MAb labeling revealed the organisms to belong to type I. On both trees, all nine atypical type I isolates that were weakly positive with QUBPa2 clustered separately from other type I strains.

\section{DISCUSSION}

Using IFM, we identified two MAbs, designated QUBPa1 and QUBPa2, which were specific for cell surface epitopes of the reference strains NCTC 737 and NCTC 10390, respectively. The MAbs were highly specific and did not react with bacteria from a range of related and unrelated genera. Due to their specificity, these MAbs may prove especially valuable for direct IFM-based detection of P. acnes types I and II from clinical specimens, such as large aggregates of $P$. acnes biofilm dislodged by ultrasound from infected prosthetic hip implants (33).

Immunogold labeling and IFM analysis revealed that QUBPa1 was specific for an antigen that accumulates at the septa and apices of type I cells. Immunoblotting experiments with whole-cell preparations of NCTC 737 revealed labeling of two bands at 61 and $68 \mathrm{kDa}$. With a purified cell wall preparation, the $61-\mathrm{kDa}$ component was absent or reduced in quantity, findings that may be related to dissociation from the cell envelope. Considering that reactivity with QUBPa1 was abolished after treatment of the antigen with proteinase $\mathrm{K}$, but not after sodium-meta-periodate treatment, it appears that the bands detected were proteinaceous. Although MAbs have specificity for a single epitope, it is not uncommon for multiple bands to be labeled on Western blots (9). Multiple bands may result from molecules that share the same epitope or from an antigen that undergoes posttranslational modification or proteolytic cleavage. For example, we have identified another cell surface protein in $P$. acnes that has a labile $\mathrm{N}$-terminal region and produces components of different molecular masses after SDS-PAGE and immunoblotting with MAbs (unpublished data). MAb QUBPa2 labeled the cell surfaces of type II strains. Immunoblotting revealed a diffuse band(s) between 30 and $40 \mathrm{kDa}$ and a single band at $21 \mathrm{kDa}$. The immunoreactivity of these bands was abolished after treatment with sodiummeta-periodate but not proteinase $\mathrm{K}$, providing evidence that these antigens share a carbohydrate or glycolipid-containing epitope. The diffuse or smeared band(s) detected at 30 to 40 $\mathrm{kDa}$ is, therefore, likely to represent a polymeric antigen with a varying number of saccharide units. Previous immunodiffusion experiments with polyclonal antisera against $P$. acnes have also concluded that cell wall polysaccharides of the organism can act as antigenic determinants $(3,4)$. A key distinction between $P$. acnes types I and II is the absence of galactose in 


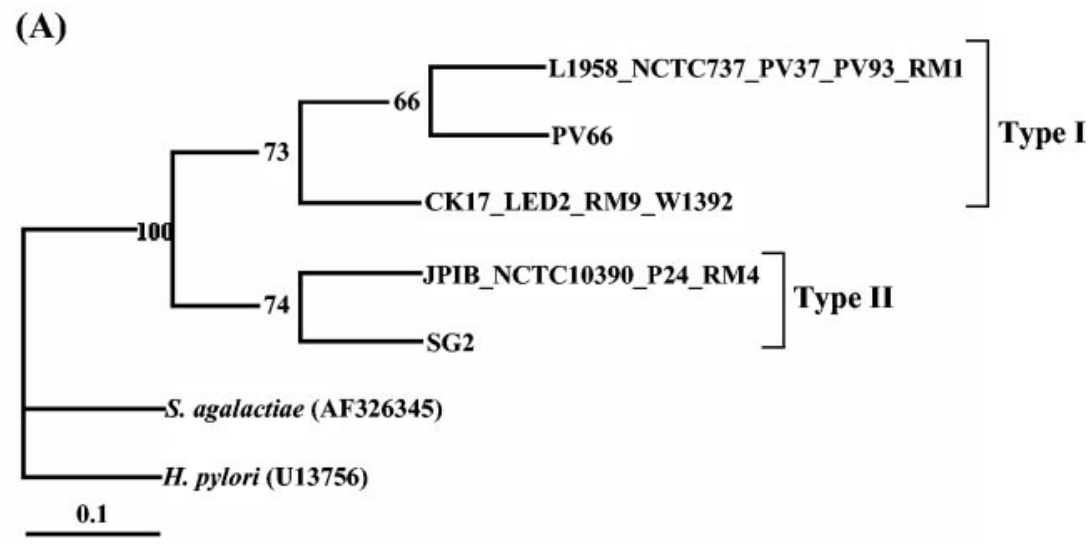

(B)

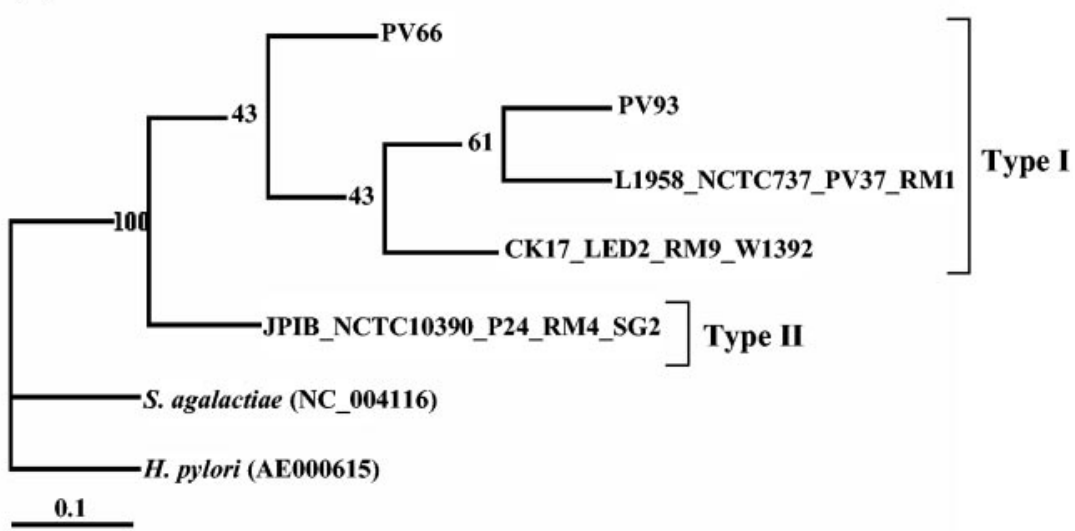

FIG. 5. Phylogenetic trees of $P$. acnes based on the complete recA (A) and tly (B) gene sequences. Multiple sequence alignments were performed on these genes and the published sequences for H. pylori (U13756 and AE000615) and Streptococcus agalactiae (AF326345 and NC_004116). The resulting phylogenetic trees were rooted with the H. pylori sequences. Bootstrapping resampling statistics were applied to the trees (100 data sets), and bootstrap values are shown at each node of the tree. The type status for the different strains analyzed is given on the right. Phylogenetic analysis was performed on a selection of isolates chosen to represent different nucleotide sequences.

the cell envelopes of type II strains (14), as well as differences in lipoglycan composition (40). Whether these features relate to the epitope recognized by QUBPa2 still remains to be determined. Currently, work to purify and further characterize the type I and II antigens is ongoing in our laboratory.

Using our MAbs, we conducted a preliminary epidemiological study of $P$. acnes isolates for type status (Table 2). Previously, by adopting strict anaerobic protocols and including a mild ultrasonication step to remove adherent bacteria growing as a biofilm, we isolated $P$. acnes as frequently as Staphylococcus spp. from implants and associated tissue of patients undergoing revision hip surgery $(33,34)$. In this study, analysis of $P$. acnes isolates recovered directly from prosthetic hip implants revealed approximately equal numbers of type I and II strains, while isolates from associated bone and tissue samples were predominantly of type I. Isolates recovered from patients with acne and dental infections, and skin isolates from surgical incision sites, were also found to be predominantly type I. Further studies with a larger group of isolates from similar patients will be valuable for confirming this distribution of types. Because skin and oral isolates appear to belong predominantly to type I, yet a significant number of type II isolates were recovered from prosthetic hip implants, it will be impor- tant to identify the exact source of these type II organisms. Analysis of $P$. acnes isolates from other sites may help address this issue and provide a better understanding of infection routes for prosthetic infections. Also, a more extensive study of type I and II distribution among oral isolates may prove particularly valuable, because dental manipulations and dentogingival infections, such as dental caries and periodontal disease, have been implicated in prosthetic joint infection through hematogenous spread $(19,30)$. P. acnes in particular has been reported to constitute up to $9.0 \%$ of the dental microbiota, and studies to recover obligate anaerobes from carious dentin indicated that approximately $20 \%$ of all isolates were P.acnes (1, 12).

Investigation of the phylogenetic relationship between $P$. acnes types I and II revealed only one type-specific base difference in the $16 \mathrm{~S}$ rRNA gene sequence, highlighting the close relationship between the two groups. Although sequence analysis of the 16S rRNA gene is widely recognized as a powerful method for investigating the phylogenetic relationship between bacteria, it may not be the most appropriate technique for distinguishing between related members of a genus or species (36). In contrast, nonribosomal housekeeping genes (e.g., rec $A$, ATP-synthase, and GroEL) have frequently been found to give 
better insights into the phylogenetic relationship that exists between closely related organisms $(15,22,37)$. In particular, analysis of the $\operatorname{rec} A$ gene has been valuable for the separation of closely related species, and bacterial classifications based on $\operatorname{rec} A$ have proved to be consistent with those obtained by using rRNA genes (6). As a consequence, we investigated the relationship between $P$. acnes types I and II based on rec $A$. Furthermore, we also examined the phylogenies of both types by analyzing a putative $P$. acnes hemolysin gene, known as tly, which we also identified from the NCTC 737 genome sequence.

Sequence analysis of the $\operatorname{rec} A$ and tly genes from a selection of $P$. acnes strains revealed a significantly greater number of conserved type-specific base differences than sequence analysis of the $16 \mathrm{~S}$ rRNA locus. Phylogenetic analysis of both the rec $A$ and tly sequences revealed that types I and II represent phylogenetically distinct groups, further demonstrating the benefits of protein-encoding DNA for systematic analysis. The agreement of the tly phylogenetic tree with that of $r e c A$ also demonstrated the value of taxon-specific genes in phylogenetic investigations. Such genes are under selective pressures different from those for universal housekeeping genes and therefore may be less well conserved, giving rise to better phylogenetic resolution of closely related organisms. Recently, analysis of 46 $P$. acnes isolates by random amplification of polymorphic DNA (RAPD) revealed two distinct genomic profiles (28). Although the type status of these various isolates was not determined, RAPD profiles from the type I and II reference strains, NCTC 737 and NCTC 10390, respectively, did match the two RAPD lineages of these $P$. acnes isolates, providing further evidence for the distinct genomic natures of types I and II. Studies of Burkholderia cenocepacia (genomovar III), which causes infections among patients with cystic fibrosis, has also revealed the presence of two phylogenetically distinct $r e c A$ lineages (known as III-A and III-B) (24). Epidemiological investigations have shown that strains of these two lineages not only differ in their distribution among infected patients in different geographical localities $(21,29)$ but also display differences in the presence of specific virulence factors (24). Two further phylogenetically distinct $r e c A$ lineages (III-C and III-D) of B. cenocepacia have also been described recently (35). Whether the different $r e c A$ lineages of $P$. acnes differ significantly with respect to virulence awaits further research.

Although the majority of $P$. acnes isolates (92\%) could be conclusively identified as type I or II based on MAb immunoreactivity, which was confirmed by DNA sequencing of a representative selection of strains, we did identify nine atypical strains that fermented sorbitol yet did not react with QUBPa1 but showed weak reactions with QUBPa2. In addition, we also detected two isolates that reacted with both MAbs, although labeling was strong with one MAb and poor with the other. $\operatorname{rec} A$ and tly sequencing of these 11 atypical $P$. acnes isolates identified them as type I. In the $\operatorname{rec} A$ and tly phylogenetic trees, all nine atypical type I isolates that were weakly positive with QUBPa2 clustered on a separate branch from other type I strains. These organisms may belong to a further phylogenetic subdivision within type I. It will be necessary, however, to perform molecular typing experiments, such as pulsed-field gel electrophoresis, to confirm that these isolates do indeed represent different strains and not a single atypical strain or clone isolated from different patients. We have also found that these atypical type I isolates express high levels of a surface and secreted antigen that is normally present in large quantities only among type II organisms (unpublished data), thus further demonstrating their distinct nature. The atypical reactions of PV66 and PV93 with QUBPa1 and QUBPa2 suggest that their exact relationship to other type I strains may warrant further investigation. Indeed, although earlier studies indicated that $P$. acnes types I and II had similar GC contents and DNA homologies (14), a more detailed polyphasic taxonomic study of these various $P$. acnes groups may now be appropriate in the light of our phylogenetic data.

The identification of type-specific nucleotide differences between types I and II has also revealed that DNA sequencing can be used as an accurate method for the identification of $P$. acnes types. Currently, we are investigating more practical DNA-based methods, such as restriction fragment polymorphism analysis and/or the use of type-specific primers, which could be used as a complement to DNA sequencing and MAb labeling.

In conclusion, phylogenetic analysis has revealed that $P$. acnes types I and II represent distinct lineages. Therefore, the well-described antigenic and biochemical differences between types I and II reflect deeper differences in their phylogeny. Improvements in the identification of $P$. acnes types I and II, and a better understanding of the organism's phylogeny, will facilitate the study of $P$. acnes epidemiology and pathogenesis.

\section{ACKNOWLEDGMENTS}

We thank Anne Eady, Carl Kamme, and William Wade for supplying a selection of Propionibacterium spp. We also acknowledge Rebecca Perera for electron microscopy, Tom Gardiner for help with confocal laser scanning microscopy, and Gisli Einarsson for technical assistance. We also thank Eshwar Mahenthiralingam for a helpful discussion regarding bacterial taxonomy and phylogenetic analysis.

A.M. was funded by a program grant from the Northern Ireland Health and Personal Social Services Research and Development Office (NIHPSS R \& D Office). S.V. was funded by an NIHPSS R \& D Office studentship and a grant from the British Orthopaedic Wishbone Trust. G.R. was funded by a Department of Employment and Learning Northern Ireland studentship, and J.V.G. was funded by a European Social Fund studentship. M.M.T. was funded by the Arthritis Research Campaign, Chesterfield, United Kingdom (project grant P0554). G.C.M. was funded by the Royal College of Surgeons of England and The British Orthopaedic Wishbone Trust.

\section{REFERENCES}

1. Ando, N., and E. Hoshino. 1990. Predominant obligate anaerobes invading the deep layers of root canal dentin. Int. Endod. J. 23:20-27.

2. Brook, I., and E. H. Frazier. 1991. Infections caused by Propionibacterium species. Rev. Infect. Dis. 13:819-822.

3. Cummins, C. 1980. Serology of propionibacteria, p. 205-221. In D. W Lambe, R. J. Genco, and K. J. Mayberry-Carson (ed.), Anaerobic bacteria selected topics. Plenum Press, London, United Kingdom.

4. Cummins, C. S., and J. L. Johnson. 1974. Corynebacterium parvum: a synonym for Propionibacterium acnes? J. Gen. Microbiol. 80:433-442.

5. Eady, E. A., and E. Ingham. 1994. Propionibacterium acnes-friend or foe? Rev. Med. Microbiol. 5:163-173.

6. Eisen, J. A. 1995. The RecA protein as a model molecule for molecular systematic studies of bacteria: comparison of trees of RecAs and 16S rRNAs from the same species. J. Mol. Evol. 41:1105-1123.

7. Funke, G., A. von Graevenitz, J. E. Clarridge III, and K. A. Bernard. 1997. Clinical microbiology of coryneform bacteria. Clin. Microbiol. Rev. 10:125159

8. Hancock, I. C., and I. R. Poxton. 1988. Bacterial cell surface techniques. John Wiley and Sons Ltd., Chichester, United Kingdom.

9. Harlow, E., and D. Lane. 1988. Antibodies: a laboratory manual. Cold Spring Harbor Laboratory Press, Cold Spring Harbor, N.Y. 
10. Higaki, S., T. Kitagawa, M. Kagoura, M. Morohashi, and T. Yamagishi. 2000. Correlation between Propionibacterium acnes biotypes, lipase activity and rash degree in acne patients. J. Dermatol. 27:519-522.

11. Holmberg, K., and U. Forsum. 1973. Identification of Actinomyces, Arachnia, Bacterionema, Rothia, and Propionibacterium species by defined immunofluorescence. Appl. Microbiol. 25:834-843.

12. Hoshino, E. 1985. Predominant obligate anaerobes in human carious dentin. J. Dent. Res. 64:1195-1198.

13. Jakab, E., R. Zbinden, J. Gubler, C. Ruef, A. von Graevenitz, and M. Krause. 1996. Severe infections caused by Propionibacterium acnes: an underestimated pathogen in late postoperative infections. Yale J. Biol. Med. 69:477482.

14. Johnson, J. L., and C. S. Cummins. 1972. Cell wall composition and deoxyribonucleic acid similarities among the anaerobic coryneforms, classical propionibacteria, and strains of Arachnia propionica. J. Bacteriol. 109:10471066.

15. Karlin, S., G. M. Weinstock, and V. Brendel. 1995. Bacterial classifications derived from RecA protein sequence comparisons. J. Bacteriol. 177:68816893.

16. Kishishita, M., T. Ushijima, Y. Ozaki, and Y. Ito. 1979. Biotyping of Propionibacterium acnes isolated from normal human facial skin. Appl. Environ. Microbiol. 38:585-589.

17. Laemmli, U. K. 1970 . Cleavage of structural proteins during the assembly of the head of bacteriophage T4. Nature 227:680-685.

18. Leyden, J. J., K. J. McGinley, and B. Vowels. 1998. Propionibacterium acnes colonization in acne and nonacne. Dermatology 196:55-58.

19. Lindqvist, C., and P. Slatis. 1985. Dental bacteremia- a neglected cause of arthroplasty infections? Three hip cases. Acta Orthop. Scand. 56:506-508.

20. LiPuma, J. J., B. J. Dulaney, J. D. McMenamin, P. W. Whitby, T. L. Stull, T. Coenye, and P. Vandamme. 1999. Development of rRNA-based PCR assays for identification of Burkholderia cepacia complex isolates recovered from cystic fibrosis patients. J. Clin. Microbiol. 37:3167-3170.

21. LiPuma, J. J., T. Spilker, L. H. Gill, P. W. Campbell III, L. Liu, and E. Mahenthiralingam. 2001. Disproportionate distribution of Burkholderia cepacia complex species and transmissibility markers in cystic fibrosis. Am. J. Respir. Crit. Care Med. 164:92-96.

22. Ludwig, W., J. Neumaier, N. Klugbauer, E. Brockmann, C. Roller, S. Jilg, K. Reetz, I. Schachtner, A. Ludvigsen, M. Bachleitner, U. Fisher, and K. H. Schleifer. 1993. Phylogenetic relationships of bacteria based on comparative sequence analysis of elongation factor Tu and ATP-synthase $\beta$-subunit genes. Antonie Leeuwenhoek J. Microbiol. Serol. 64:285-305.

23. Lutton, D. A., S. Patrick, A. D. Crockard, L. D. Stewart, M. J. Larkin, E. Dermott, and T. A. McNeil. 1991. Flow cytometric analysis of within-strain variation in polysaccharide expression by Bacteroides fragilis by use of murine monoclonal antibodies. J. Med. Microbiol. 35:229-237.

24. Mahenthiralingam, E., J. Bischof, S. K. Byrne, C. Radomski, J. E. Davies, Y. Av-Gay, and P. Vandamme. 2000. DNA-based diagnostic approaches for identification of Burkholderia cepacia complex, Burkholderia vietnamiensis,
Burkholderia multivorans, Burkholderia stabilis, and Burkholderia cepacia genomovars I and III. J. Clin. Microbiol. 38:3165-3173.

25. McGinley, K. J., G. F. Webster, and J. J. Leyden. 1978. Regional variations of cutaneous propionibacteria. Appl. Environ. Microbiol. 35:62-66.

26. Patrick, S., and D. A. Lutton. 1990. Outer membrane proteins of Bacteroides fragilis grown in vivo. FEMS Microbiol. Lett. 59:1-4.

27. Patrick, S., L. D. Stewart, N. Damani, K. G. Wilson, D. A. Lutton, M. J. Larkin, I. R. Poxton, and R. Brown. 1995. Immunological detection of Bacteroides fragilis in clinical samples. J. Med. Microbiol. 43:99-109.

28. Perry, A. L., T. Worthington, A. C. Hilton, P. A. Lambert, A. J. Stirling, and T. S. J. Elliott. 2003. Analysis of clinical isolates of Propionibacterium acnes by optimised RAPD. FEMS Microbiol. Lett. 238:51-55.

29. Speert, D. P., D. Henry, P. Vandamme, M. Corey, and E. Mahenthiralingam. 2002. Epidemiology of Burkholderia cepacia complex in patients with cystic fibrosis, Canada. Emerg. Infect. Dis. 8:181-187.

30. Sullivan, P. M., R. C. Johnston, S. S. Kelley, and D. Moines. 1990. Late infection after total hip replacement caused by an oral organism after dental manipulation. J. Bone Joint Surg. Am. 72:121-123.

31. Tancrede, C. 1992. Role of human microbiota in health and disease. Eur. J. Clin. Microbiol. Infect. Dis. 11:1012-1015.

32. Thompson, J. D., D. G. Higgins, and T. J. Gibson. 1994. CLUSTAL W: improving the sensitivity of progressive multiple sequence alignment through sequence weighting, position-specific gap penalties and weight matrix choice. Nucleic Acids Res. 22:4673-4680.

33. Tunney, M. M., S. Patrick, M. D. Curran, G. Ramage, D. Hanna, J. R. Nixon, S. P. Gorman, R. I. Davis, and N. Anderson. 1999. Detection of prosthetic hip infection at revision arthroplasty by immunofluorescence microscopy and PCR amplification of the bacterial 16S rRNA gene. J. Clin. Microbiol. 37:3281-3290.

34. Tunney, M. M., S. Patrick, S. P. Gorman, J. R. Nixon, N. Anderson, R. I. Davis, D. Hanna, and G. Ramage. 1998. Improved detection of infection in hip replacements. J. Bone Joint Surg. Br. 80:568-572.

35. Vandamme, P., B. Holmes, T. Coenye, J. Goris, E. Mahenthiralingam, J. J. LiPuma, and J. R. Govan. 2003. Burkholderia cenocepacia sp. nov.-a new twist to an old story. Res. Microbiol. 154:91-96.

36. Vandamme, P., B. Pot, M. Gillis, P. de Vos, K. Kersters, and J. Swings. 1996 Polyphasic taxonomy, a consensus approach to bacterial systematics. Microbiol. Rev. 60:407-438.

37. Viale, A. M., A. K. Arakaki, F. C. Soncini, and R. G. Ferreyra. 1994. Evolutionary relationships among eubacterial groups as inferred from GroEL (chaperonin) sequence comparisons. Int. J. Syst. Bacteriol. 44:527-533.

38. Vuong, C., and M. Otto. 2002. Staphylococcus epidermidis infections. Microbes Infect. 4:481-489.

39. Webster, G. F., and C. S. Cummins. 1978. Use of bacteriophage typing to distinguish Propionibacterium acnes types I and II. J. Clin. Microbiol. 7:8490.

40. Whale, G. A., I. C. Sutcliffe, A. R. Morrisson, E. L. Pretswell, and N. Emmison. 2004. Purification and characterization of lipoglycan macroamphiphiles from Propionibacterium acnes. Antonie Leeuwenhoek 86:77-85. 